\title{
A Research on Process of Interaction Between Business Intelligence (BI) and SMES
}

\author{
S.S. Bhosale, R.B. Patil
}

\begin{abstract}
Business Intelligence (BI) also, SMEs square degree unmistakable examination areas anyway large cooperation amongst the ones factors can deliver the a achievement benefit from every other. This collaboration has been thinking about in main the dynamic climate. This connection will exclusively beautify singular bits of expertise of BI and SMEs, it adds to the business enterprise herbal execution. despite the fact that examination on BI and SMEs is tremendous so far, restricted spotlight was given on studying detail among Bi and SMEs. Thusly, this investigation is expected to accomplice examinations writing and investigates an incorporated study of writing broke down on anyway BI and SMEs benefit from every other and affords to the economic business enterprise ecological execution. A subjective substance examination have become directed for the approach that considers forty three articles for information deliver. Discoveries of the writing audit prescribe upgrading capacity of SMEs and new advancement of Bi, that might affect each different. Discoveries of this research may also become supportive for additonal examination regarding Bi usage success
\end{abstract}

Watchword: commercial enterprise know-how; SMEs; adjustment; functionality; name making; intuitive connection; and getting to know.

\section{INTRODUCTION}

Business intelligence (BI) Has been elevated gratitude to its increasing commitment to like organization execution warranty, information records warehousing, arranging, guaging, planning, and the number one management, and furthermore the higher highbrow technique that aides enterprise interest in the direction of desired execution. BI's growing commitment to the industrial employer developing execution has been perceived essentially for little and medium endeavors (SMEs) (through up name aid. these days BI ends up associate sample in managing the selection making for predominant the dynamical surroundings, and figuring out the manner to require openings growing kind dynamical conditions.

BI is companion in statistics framework (IS) valuable stone rectifier software program that coordinates the approach and innovation to guide for the choice making for supervisors and finish clients. It assumes a noteworthy interest in investigating the enterprise climate and giving the choice making in wearing out aggressive advantages ascending from unsure extra often than now not adjustments inside the air. This commercial employer environment is

Revised Version Manuscript Received on 16 September, 2019.

S.S. Bhosale, Research Scholar, Department of Computer science and engineering, Shri JJTU, Rajasthan, India.

(Email: sachin1978in2002@yahoo.com)

R.B. Patil, Professor, Department of Computer science and engineering, S.K.Somaiya College of Arts, Science and Commerce, Mumbai, Maharashtra, India.

(Email: patilrajendrab@gmail.com) defined with political precept and monetary strength, multifaceted nature of overdue records, unfastened show off trade, and immoderate stress of opposition inferable from expedient growing pace of current development. The growing pace of modern development intensified memorable length in the international. growing affects of statistics frameworks, new growing in innovation, speedy memorable period, and furthermore the monetary machine reason commercial enterprise environment is gradually being increasingly more tempestuous this is on the far component the control functionality of SMEs. Age in the business competition makes new possibilities and dangers for corporations that come to be the difficulty of employer patience and development. Accepting open doors and experiencing amazing risks open a test for SMEs. accordingly, auditing and rebuilding the commercial enterprise call end up on need.

regardless of the economic duration of each agency, get admission to to enormous and fundamental information is imperative to affirm the fulfillment of the securing of a bit of the general organisation. enterprise perception is considered a dreadfully important tool to accomplish such an goal. according with the Gartner's critiques, commercial enterprise perception (BI) and studies frameworks are stratified because the high revolutionary need of agencies in the most present day years round the arena. The maximum purpose of bismuth frameworks is to inspire the choice making method by using giving great data, in view of the exam of significant measures of inward and outer records. Be that as it could, BI frameworks are described via their trouble and nice to address. additionally, economic elements are those who collect some SME's corporations forget about to keep to the procurement of a framework. often, the development and support of a bismuth framework calls for essential financing. except, most of SMEs don't have a particular IT workplace. a few SMEs are journey by using the use of the owners, WHO won't have progressed revolutionary information. it's miles-celebrated that the utilizations of bismuth are not basically open to SMEs. The to be had frameworks are overvalued, difficult to make use of and require thoughts-blowing revolutionary training of enterprise workers.

generally, these programs meet the goals of large ventures that have all the turning into assets for his or her proper operating. no matter these impediments, higher statistics association, facilitated with the aid of a bismuth framework, can also bring about higher selections and end up a everyday 
upper hand. An crucial is that the independent showdown of problems, originating from the appropriate attributes of SMEs. With the advancement of innovation, bismuth vendors have installed and created packages and instruments to satisfy real independent companies wishes. There are bismuth frameworks which is probably available on-line. these frameworks are lower priced, straightforward and that they have got an area with the elegance of cloud frameworks. Such preparations are proper for SMEs, as they may be doing now not motive additional established order and help esteem. devices and IT framework applications aren't thought of a gain of fantastic partnerships, given that the administrations supplied are supposed for the wishes and stipulations of SMEs, which may be even as aggressive and independent. the present paper has a tendency to an huge variety of troubles related to the usage of bismuth frameworks in SMEs. BI professionals and SME chiefs may additionally see this impermanent besides elliptic file supportive in their motives an task to utilize this to extremely-cutting-edge innovation all through this precise region.

\section{LITURATURE SURVEY}

\subsection{SMEs and choice situation:}

SMEs rectangular degree laid out as highly modest estimated businesses rectangular measure (an) correctly overseen by means of the use of their home proprietors, very custom designed, for the most component local of their space of obligations, and usually fixated on indoors wellsprings of funding to decrease back their improvement. SMEs are perceived for their growing commitments to a country's monetary advancement. The constant and increasing willpower of SMEs could be seen "in giving monetary advantage producing bodily video games so increment the rate of development of true consistent with capita financial gain, balance financial advantage dispersion and enhance economic solidness". They need been taking a reputedly big little bit of the planet financial development seeing that Nineteen Forties however, proprietors/directors of SMEs unendingly face a ramification of troubles associated with amazing changes inside the surroundings (for instance advertise competition, mechanical development, and commercial business enterprise dynamisms).

speed of revolutionary updating amasses new contenders, exhibit, new item, and new commercial enterprise technique in a very large device. The rapid tempo of mechanical progress makes the inventory of vulnerability, international project, and competitive electricity for organizations. On the opposite hand, targeted strain influences new early inside the mechanical segment, while variables like market rivalry, enterprise approach and global affiliation square degree interconnected. In fact, adjustments in customer expenses, show off requests, valuing, and deliver chain the board square degree apparent. the ones progressions deliver each danger, (as an example, adaptability, low absolutely worth systems administration, esteem lower, and fast correspondence (as an example information protection hazard, forestall of enterprise request), that end up the problem of commercial enterprise endurance and development of SMEs. Be that as it can, accepting open doorways and experiencing dangers become a test for SMEs for changing agencies at the a ways thing the ones adjustments. subsequently, essential better intellectual manner seems essential that aides directors within the route of this appreciate.

the choice making is laid out given that the selection of interest and tool administrators/establishments use to guide the continuously converting surroundings recognized with quick responsiveness it is associate coordinated approach for determinative industrial business enterprise execution diploma, setting apart name issues, assimilative facts, expectation agency future, and taking into consideration sports activities toward the predefined execution). For adequacy of the selection making, it's essential to understand the selection surroundings. the call surroundings reflect onconsideration on the inventory of call downside, name desires, and pertinent property. on this manner, businesses rectangular degree dynamically and for the maximum detail looking on ampleness and precision of facts offer chain. In reality, facts the board seems to be important for the choice making in SMEs.

information the board alludes to overseeing requiring information supply chain, its osmosis, and its transformation right into a substantial sort to makes its ease of use information the board offers the big technique in pleasing associations' records essentially based totally totally wishes. considering, statistics the executives gives starting, collecting, putting away, recording, breaking down, mixing, and reworking data, that produce statistics essential to the choice making records the board coordinates three software for three consequences like innovation basis fulfills material essentially based totally wishes, data affiliation makes its ease of use, and statistics business enterprise for its actual use into the decision making software). despite the fact that it's miles been perceived for the decision making adequacy, the exam will increase a want to steer facts the board in agencies. eventually, IS-drove utility progresses towards turning into on want so one can provide a thoroughness of data the board for and speak to help. As in advance communicated that steel thing has been importance as seems to be driven business organisation software that incorporates each datum the executives for and in this way the higher subjective way assist. in the end, metal component usage finally ends up industrial corporation easy for getting a charge out of two reticulated jobs such facts the executives and on this way the better mental system for change adjustment in SMEs.

\section{2. process of $B I$}

commercial enterprise perception (BI) is sketched out as "the strategy for blend studying of getting to know of records from numerous internal and outer information property, making use of investigation apparatuses and techniques to recognize the information inside the statistics, making choices, and taking sports reinforced this picked up understanding" The significance of metallic issue might be fanciful with the resource of know-how the inquiries that for what purpose will metal difficulty maintain holding its excessive comparing function and why have organizations now not finished the execution of BI-drove software. joining of information from unique assets, message extraction from

Published By:

Blue Eyes Intelligence Engineering 
given information for and alongside those lines the better subjective manner makes the price of metal component software program. The higher than speak speaks to that metallic aspect assumes in considerable interest of an organization execution the board (Richards et al., 2011) through fundamental information the executives and alongside the ones traces the better subjective method institutions would possibly need for directing the often converting environment.

regarding the data the executives, new and entangled facts ascending from in no manner-endingly taking vicinity adjustments inside the surroundings open a test for SMEs. on this manner, establishments want assimilative and approach information for sleuthing the extent of affects of those progressions with a view to inspire institutions to require the dynamic call. steel detail has been multiplied in view of its effective software program for dispersing, assimilative, and manner information corporations use to find troubles associated with the choice making. For materiality of the choice making, metal factor as partner IS LED utility gives the ok degree of studying exactness and class of information that produces substantial information. information offers concerning what has occurred; what's happening and what also can stand up. The records gives establishment of the choice making with apprehend to what to be completed and the manner. honestly, steel element has grew to become out to be apparent as coherent empowering agent of facts the board that may be a key want of the choice making.

With appreciate to the choice making, metallic thing makes the business enterprise simply worth pursued via consumer participation, correction adjustment, and rapid responsiveness to competitive necessities. besides, the choice making gives the properly well worth reasoning, adaptability of imparting, new innovation preference, organization hobby guiding principle nice information sooner or later ends up primary for the usual call. satisfactory data rises up out of an intensive studies between recorded basis and current surroundings. learning chronicled setting and cutting-edge scenario offers the $\$ 64000$ deliver of data extraction. metal detail makes use of advantageous advances to coordinate chronicled and modern-day-day getting to know recording, integrates, gaining knowledge of trade into records, records age, and its abuse into the choice making to improve the enterprise productivity. commonly, the speak speaks to that steel trouble will become a superb trouble of main the choice making identified with right facts the board. The interrelatedness amongst metallic factor, facts the board, and in this way the higher mental technique has been engaged with showing the ensuing.

\section{3. relationship amongst's $S M E$ and $B I$}

Off-base or terrible name may additionally need to likewise be danger of business business enterprise endurance and improvement. along those strains, metallic aspect reveals troubles related with the selection making via overseeing statistics) and creates the equal antique call. in any case, it is not confirm that drastically identical metal aspect is suitable for all enterprises because, without a doubt businesses have numerous factors and diverse perspectives on metal problem execution. on this manner, equal metal element isn't turning into for SMEs as utilized in massive organizations. considering, numerous confinement likes series of employees, each yr turnover, hypothesis on IS, and lengthy long past ahead venture square degree the additives to examine the form detail of SMEs. Decisively, metallic difficulty association needs to suits SME's form elegant.

In examination, steel difficulty gives the selection making help SMEs requirement for leading correction adaption in companies. similarly, SMEs need new development or renewal of metal element for requiring new bring in directing new changes happens inside the environment. In differentiation, SMEs square degree debilitated as a long way as required capability for essential metallic element utilization. It gives the concept that SME's new call is predicated upon steel trouble improvement and new improvement of metallic element relies upon SME's vital capability. ultimately, our investigation to spot and inspect an included take a look at of IS writing with appreciate to anyway metallic component and SMEs gain from every other, that may upload to the IS-drove commercial enterprise development. along those strains, we can in popular direct a writing audit to determine substance good sized to the prevailing examination placing and make a topical connection among the ones substance for spotting favored cease of this research.

\section{METHODOLOGY \& RESULTS}

\section{1. examine plan}

organized writing survey finds the ebb and go with the flow circumstance of studies inside the proposed studies subject and degree to which greater research is required (Webster and Watson, 2002). We along those traces lead a writing audit that gives assembling a hypothetical system thinking about a connection amongst's BI and SMEs, which might also upload to enhance singular bits of information of the 2 substances. From this concept driven writing survey we intend to research agreeable connection of BI and SMEs and its integrated impacts into IS-drove agency improvement. As our investigation directs the substance based totally exam for facts the social attitude on given substance in emotional way as opposed to checking way, the subjective substance research has been led for the technique. Subjective substance investigation coordinates topical views on decided on articles and proposes a hypothetical form depending on topical connection. therefore, we taken into consideration great diary and meeting databases for surveying excellent articles essential to the exam putting.

organized writing survey finds the ebb and waft circumstance of research within the proposed research location and degree to which greater studies is wanted (Webster and Watson, 2002). We in this way direct a writing audit that offers assembling a hypothetical form thinking about a dating amongst's BI and SMEs, which may additionally upload to pork up individual bits of information of the two materials. From this idea pushed writing survey we plan to analyze agreeable collaboration of BI and SMEs and its included influences into IS-drove business enterprise development. As our examination directs the substance based

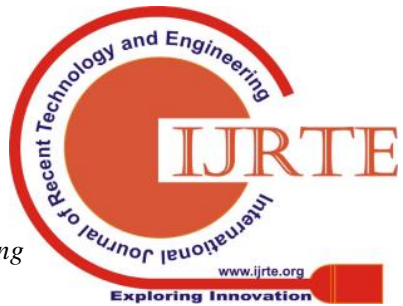


totally research for know-how the social angle on given substance in emotional way instead of checking manner the subjective substance research has been led for the system. Subjective substance examination consists of topical views on selected articles and proposes a hypothetical machine dependent on topical connection. on this manner, we considered high-quality diary and meeting databases for checking on first-rate articles pertinent to the research setting.

\subsection{Writing looking}

"a complete survey covers tremendous writing on the topic and isn't always restricted to 1 research device, one lot of diaries, or one geographic locale" consequently, the mission became screened on the pinnacle in searching through pertinent writing making use of electronic databases within the challenge. We attempted to make use of key huge diaries (for example MIS quarterly, records structures magazine, statistics and control, decision help structures, global magazine of statistics management, interchanges of the relationship for records frameworks, business Intelligence magazine, journal of global data technology control, global magazine of Operations and production management, worldwide magazine of business information systems, and so forth) and gathering techniques (as an example IEEE gathering, ACIS, medical and Technical statistics Processing, AMCIS, and AISel). As BI and SMEs are crucial region of our investigation, we started writing seek using "BI AND SMEs" as important catchphrase. it's far vital to be aware of that earlier seek offers severa watchword for following hunts. consequently, our first seek proposed numerous catchphrases, for instance, change adjustment, functionality, easy management, intuitive connection, analyzing execution. We applied those catchphrases for searching through writing and diverse pertinent written works changed into at final selected for facts sources.

\subsection{Writing strength of will approach}

Writing willpower approach has been directed by means of the usage of thinking about studies of regarded through articles. The outline of article preference system has been added into the accompanying figure 2. Albeit diverse hits became taken to leaf through relevant articles, 52 articles have been downloaded from the ones hits. All downloaded articles were spared in an individual organizer to be unique "BI and SMEs". right off the bat, those articles were screened with the aid of manner of directing conceptual audit. After basically checked on of every selected article, 11 articles have been barred in view of not coordinating precisely to our studies setting. Staying forty one articles have been essentially chosen for the facts source, that are firmly identified with wanted discoveries. A mixture of bits of expertise and listing of resources rundown of selected articles proposed similarly are seeking for, which protected progressively 2 articles into the pool. At long remaining, $41+2=$ forty three articles were selected for the dedication to this exam.
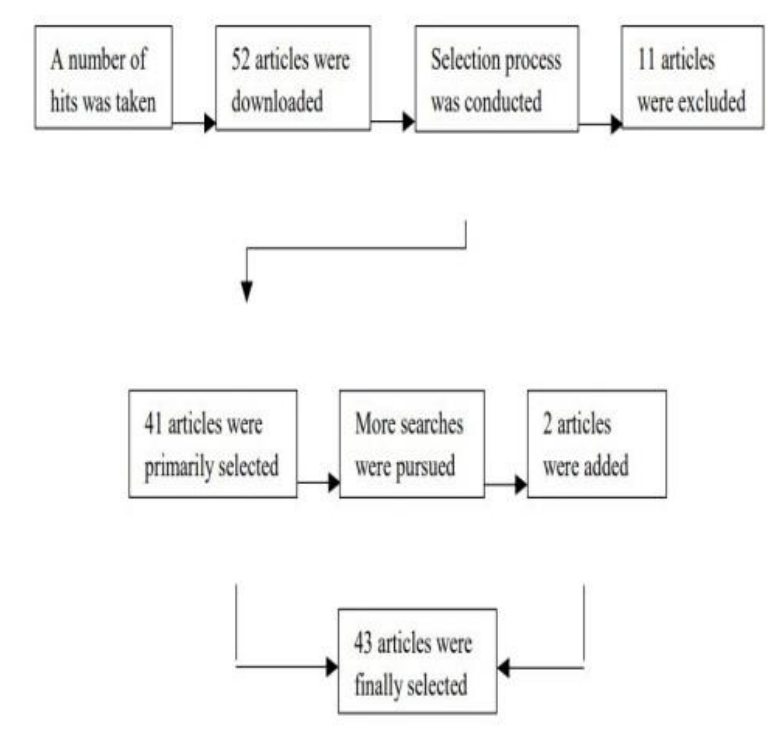

Figure 1: Literature selection process

\section{4. data studies process}

This paper has been guided by using using (Orlikowski and Barley 2001), as an extended way as concept age. (Orlikowski and Barley 2001) focused on epistemological connection among two unmistakable materials, for example, facts innovation (IT) and association, which collaborate each exceptional agreeably. We procured this concept to apprehend epistemological connection amongst BI and SMEs as are substances, which could earnings each other. BI possesses deserves with, for example, statistics warehousing, statistics mining, message extraction for choice assist (Singh and Singh, 2013) and SMEs deliver degree to which BI obtains front (Grabova et al., 2010). As referenced earlier than that our research searches for how they can be agreeably interfaced that reasons improvement of their individual critiques and the way this verbal exchange reasons new determination into the IS-business agency area. on this manner, an integrative facts exam has been tried for extricating the triumphing circumstance of getting to know diagnosed with previously cited wanted outcomes inner decided on test articles (Smith et al., 2009). Albeit 43 articles had been selected for audit, 26 articles had been concluded and brought into the accompanying table for substance research, that is coordinated through to residual articles. Paper finish for being accounted for turned into organized dependent on topical connection. 


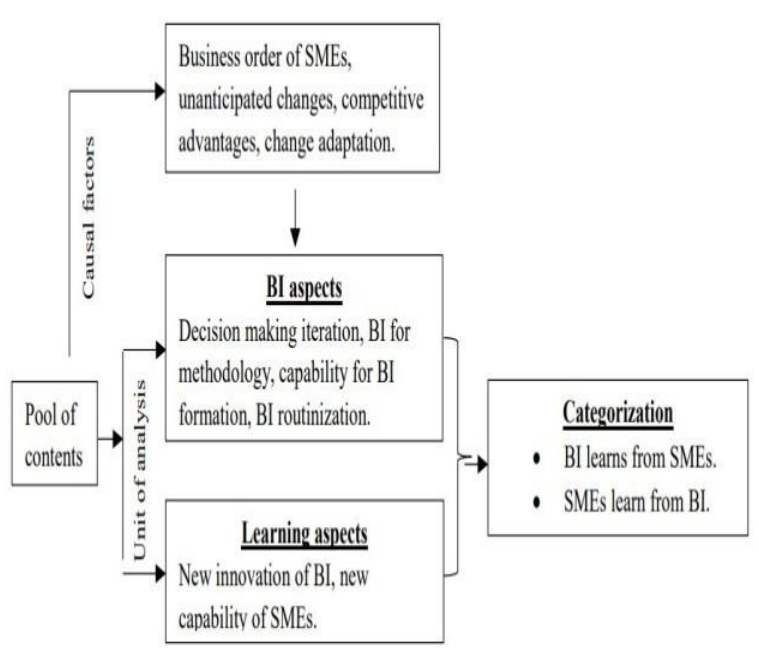

Figure 2: Data analysis and categorization

As appeared in 2, given substance in desk 1 had been exhibited into units, as an example, causal additives and unit of studies. no matter the reality that the primary set (causal factors) has no longer instantaneous determination to the facts examination, it's been accounted for into the above determine for centering why $\mathrm{BI}$ is extensive for the fundamental management in SMEs. second set (unit of investigation) speaks to coded subjects had been given from given substance, exam of subjects, and deliberation of broke down subjects. The association speaks to the essential factor discoveries of this research.

\section{ACKNOWLEDGMENTS}

I need to thank each person who help me in diverse manner. in particular i'm thankful to my aides Dr. R.B. Patil for him steady help and direction in my paintings.

\section{CONCLUSION}

The component of this research changed into to investigate a coordinated mind-set on past examinations via a hypothetical examination that how BI and SMEs collaborate each other, which may additionally additionally have positive effects in, as an instance, fortifying individual reviews of them, improving industrial organization ecological execution, and new statistics age into the exploration concern of IS. There are troubles had been basically considered in beginning this exam. first of all, SMEs are portrayed with varied confinements, which oblige business enterprise relied on execution. 2nd, dubious frequently herbal modifications have an effect on SMEs forestall their organisation execution request. for brand spanking new comprehension of the manner SMEs can choose up conditions growing up out of these progressions offers an studies. Thusly, this research has been concerned and endeavored to survey writing in connection to a hypothetical results in such way.

Our writing survey recognizes that marketers/chiefs of SMEs are popular to encompass new organization strategy because developing adjustments within the earth. pace and consistency of recent in innovation and its quick affects in mechanical disenchanted reason increasingly fierce inside the present commercial company state of affairs. New and complicated facts due to modern improvement makes new changes in, for instance, consumer dispositions, objects and administrations, production network the executives, enterprise method, and market technique. the ones dubious regularly adjustments make severa probabilities and risks, which turn out to be the problem of business agency patience and development of SMEs. anyways, change adjustment emerge as a check for accepting open doorways and experiencing unexpected risks. exchange adjustment requires looking into and reshaping current business preference that aides administrators in leading trade adaption.

The number one control calls for a appropriate degree of facts the executives. along the ones traces, problems, as an instance, data the board and the basic leadership have moved in the direction of becoming on need for alternate adjustment As BI offers enterprise execution the executives (Richards et al., 2011), our studies taken into consideration BI usage in SMEs for steering information the board and the essential control. on this way, facts the board capability has coherently been perceived for BI usage. As SMEs have severa confinement as a long way as required functionality, our discoveries propose carrying out facts the executives potential that contains mechanical and staff capabilities for BI usage in SMEs. in addition writing regarded into outstanding that information the board functionality relies upon hierarchical capacity that consists of company's assets and reviews. From the above discourse, our examination has observed that the want of BI execution for exchange adjustment in agencies allows SMEs to look at in changing their hierarchical structure pursued with the resource of reception of required functionality. no matter the truth that SMEs observe for BI utilization for the easy management as far as alternate adjustment, the consistency of converting marvels stays a fear.

with the intention to direct questionable often changes, SMEs require new desire. As BI is the superb conductor of the easy leadership, repeating the primary leadership calls for the reiteration of BI software. consequently, transformation or new development of BI ends up easy for repeating the selection to direct taking place modifications. in addition, SMEs request numerous improvement of BI as identical BI suits all. essentially, the research has perceived two troubles from writing broke down, as an example, new choice for leading new modifications and authoritative substance of SMEs, which raised the hassle of latest improvement of BI. consequently, BI profits from SMEs.

what's greater, our exam has moreover perceived that the smart connection of BI and SMEs offers the wellspring of reading viewpoint, which fortifies their man or woman function. The intuitive getting to know system produces a coordinated determination to the economic corporation ecological execution. for example, SME's robust functionality motives BI execution in emphasizing the primary control and new improvement of BI improves SME's exhibition in directing the essential management applicable to trade adjustment. in the long run, enterprise condition achieves income with the aid of way of this clever 
connection. Taking the whole lot below attention, our discoveries advocate upgrading vital capability of SMEs and recognizing suitable utilization of BI for engaging in top palms growing up out of commonly evolving scenario. in spite of the fact that what kind of capability SMEs require has been examined over, the software program kind of BI but to center. on this manner, further research is suggested in recognizing sizeable development of BI utility regarding adjustments adjustment in organizations.

\section{REFERENCES}

1 AL-MA, M. A. 2013. The position of business Intelligence tools in decision Making procedure. worldwide journal of pc packages, seventy three.

2 ANJARINY, A. H., ZEKI, A. M. And HUSSIN, H. Surveying establishments coaching closer to enterprise understanding frameworks: a proposed theorized model. Propelled laptop technological know-how applications and technology (ACSAT), 2012 worldwide conference on, 2012. IEEE, 213-218.

3 ANTLOVA, ok. 2009. thought and barriers of ICT Adoption in Small and Medium expected enterprises. E + M EKONOMIE A management, 2, a hundred and forty-a hundred and fifty five.

4 APULU, I., LATHAM, A. A. And MORETON, R. 2011 Variables influencing the viable usage and appropriation of sensitive ICT preparations: Case investigations of SMEs in Lagos, Nigeria. Diary of systems and information era, 13, a hundred twenty five-143.

5 AVGEROU, C. 2008. facts structures in growing nations: A basic studies survey. Diary of records era,23(3).

6 BADEN-FULLER, C. And HAEFLIGER, S. 2013. Plans of movement and mechanical development. long variety arranging, 46, 419-426.

7 BAPTISTA, J. 2009. Standardization as a machine of transaction amongst innovation and its authoritative setting of utilization. Diary of records innovation, 24, 305-319.

8 BARNEY, J. 1991. company assets and continued higher hand. Diary of the board, 17, 99-100 and twenty.

9 BIJKER, M. And HART, M. factors Influencing Pervasiveness of Organizational commercial enterprise Intelligence. BUSTECH 2013, The $1 / 3$ international convention on enterprise Intelligence and technology, 2013. 21-26.

10 BLOME, C., SCHOENHERR, T. And REXHAUSEN, D. 2013. Precursors and empowering influences of keep community spryness and its impact on execution: a powerful capacities point of view. well-known journal of manufacturing studies, 51, 1295-1318.

11 BRINKHUES, R., MAÇADA, A. C. And CASALINHO, G. 2014. information control abilities: Antecedents and effects. twentieth Americas convention on information structures, Savannah, AISel.

12 BURTON, B., GEISHECKER, L., HOSTMANN, B., FRIEDMAN, T. And NEWMAN, D. 2006. Hierarchical shape: business agency insight and data the board. Gartner research.

13 BUSTOS, E. S. And VICUÑA, S. D. 2016. simple management AND model techniques TO climate exchange. Ambiente and Sociedade, 19, 215-234.

14 CAVALCANTE, S., KESTING, P., and ULHOI, J. 2011. Plan of movement elements and innovation:(Re) setting up the lacking linkages. The executives selection, 40 nine, 1327-1342.

15 CHAI, J., LIU, J. N. okay. A. And NGAI, E. W. T. 2013. usage of number one leadership strategies in employer willpower: A planned audit of writing. grasp structures with packages, forty, 3872-3885.
16 CHEN, H., CHIANG, R. H. And story, V. C. 2012 business Intelligence And Analytics: From large statistics To big impact. MIS quarterly, 36, 1165-1188.

17 CHEN, X. And SIAU, okay. 2012. impact of enterprise Intelligence and IT Infrastructure Flexibility on Organizational Agility. thirty third international convention on data structures, Orlando, AISel.

18 CHI, T., KILDUFF, P. P. And GARGEYA, V. B. 2009. association amongst business agency scenario developments, focused desires, production network systems, and business enterprise enterprise execution. international journal of profitability and execution the board, 58, 645-669.

19 CITROEN, C. L. 2011. The task of facts in important basic control. international magazine of facts management, 31, 493-501.

20 DODSON, G., ARNOTT, D. And PERVAN, G. 2008. the use of business facts frameworks in Australia. 19thAustralasian convention on information systems, three-five Dec 2008, Christchurch. [ Links ]

21 DOUCEK, P. 2015. The impact of records management. FAIMA business and control magazine, three(three), five-11.

22 ELO, S. And KYNGÄS, H. 2008. The subjective substance investigation approach. Diary of lowering thing nursing, sixty, 107-115.

23 ENGLE, N. L., DE BREMOND, A., MALONE, E. L. And MOSS, R. H. 2014. towards a versatility marker structure for deciding on environmental trade adjustment alternatives. relief and edition techniques for worldwide trade, 19, 1295-1312.

24 FAITIRA, M., EDISON, G. A. And KUDAKWASHE, G. 2012. boundaries To The Adoption Of ICT with the aid of SMEs In Zimbabwe: An Exploratory look at In Chinhoyi District. foundation of Interdisciplinary business studies ., four, pp 1142-1156.

25 FINK, L. And NEUMANN, S. 2007. selecting up readiness thru IT paintings force skills: The intervening task of IT framework capacities. Diary of the association for records systems, eight, 440.

26 FITZGERALD, M., KRUSCHWITZ, N., BONNET, D. And WELCH, M. 2014. greedy automatic 